\title{
Development of an Ultimate-high-efficiency Motor by utilizing High-Bs Nanocrystalline Alloy
}

\author{
Yuji Enomoto $^{* a)}$ Senior Member, Kenta Deguchi* Member \\ Takao Imagawa* Non-member
}

In order to increasing the efficiency of axial gap motors, a motor was designed to achieve an efficiency of $98 \%$ based on the IE 5-11 kW motor (motor efficiency of 96\%). Based on the design, we created a prototype with ceramic housings, thinned coil conductors, and nanocrystalline materials for the stator core as real items to reduce losses. We verified its effect by evaluating the motor characteristics. As a result, it was confirmed that the prototype can achieve a motor efficiency of $98.3 \%$ at 3,000 min-1 and $11 \mathrm{~kW}$ rated driving. Moreover, in the temperature rise test, it was demonstrated that class $\mathrm{B}$ type $\left(130^{\circ} \mathrm{C}\right)$ could be achieved.

Keywords: high-Bs nanocrystalline alloy, axial gap type motor, motor efficiency, magnetic characteristics

\section{Introduction}

In recent years in the field of industrial motors, developing motors with higher efficiency has become an urgent need ${ }^{(1)(2)}$. In line with the recent trend toward preventing global warming, reducing power consumption of motors has been attracting attention. The IEC (International Electrotechnical Commission) stipulates the International High-efficiency Standards (IE Code) for industrial motors ${ }^{(3)}$. In IEC60034-30-1, published in 2014, the standard values for efficiency class up to IE4 are given, and as for IE5, the view that loss should be reduced by $20 \%$ in comparison with IE4 class is stated. In Japan, in April 2015, regulations for industrial motors formulated under the "Top Runner Approach" were launched. As a result, manufacturers of industrial motor are obliged to sell motors that satisfy the IE3 efficiency class or higher.

The authors have been developing basic technology for axial-gap motors that can adopt iron-based amorphous metal for the iron core in a manner that improves the efficiency of the motor ${ }^{(4)(5)}$. After that, we succeeded in trial manufacturing an $11-\mathrm{kW}$ motor that achieves motor efficiency (about 96\%) conforming to IE5 ${ }^{(6)(7)}$. However, motors with higher efficiency are required for applications that operate as a power sources for industrial use, such as industrial pumps, fans, and air compressors.

In light of the above-described circumstances, aiming to attain higher motor efficiency, we decided to study the application of high-saturation-flux-density (Bs) nanocrystalline alloy-with higher saturation magnetization and lower core loss compared to iron-based amorphous metals - to an axialgap motor. In this study, various factors related to reducing loss were considered with the goal of reducing loss by half in

a) Correspondence to: Yuji Enomoto. E-mail: yuji.enomoto.tf@ hitachi.com

* Hitachi, Ltd. Research \& Development Group

7-1-1, Omika-cho, Hitachi, Ibaraki 319-1292, Japan regard to an IE5-class-efficiency motor, and a prototype motor was designed and evaluated, and the results of that evaluation are presented hereafter.

\section{High-Bs Nanocrystalline Alloy}

2.1 Comparison with Magnetic Properties of Soft Magnetic Materials The characteristics of various soft magnetic materials are compared in Fig. $1^{(8)-(10)}$, where iron loss $\left(\mathrm{W}_{15 / 50}\right)$ under excitation of $1.5 \mathrm{~T}$ at $50 \mathrm{~Hz}$ is plotted on the horizontal axis, and magnetic flux density $\left(\mathrm{B}_{50}\right)$ under excitation with magnetic-field intensity of $5000 \mathrm{~A} / \mathrm{m}$ is plotted on the vertical axis. High-Bs nanocrystallineline alloy has superior magnetic flux density and lower core loss compared to other soft magnetic materials, such as magnetic steel sheets and pressed-powder cores, and it has material properties that can contribute to improving motor efficiency. The magnetic properties of the nanocrystallineline alloy, iron-based amorphous metal, and magnetic steel sheet are compared in Table $1^{(11)-(14)}$. According to Table 1, although nanocrystallineline alloys have lower saturation flux density Bs than

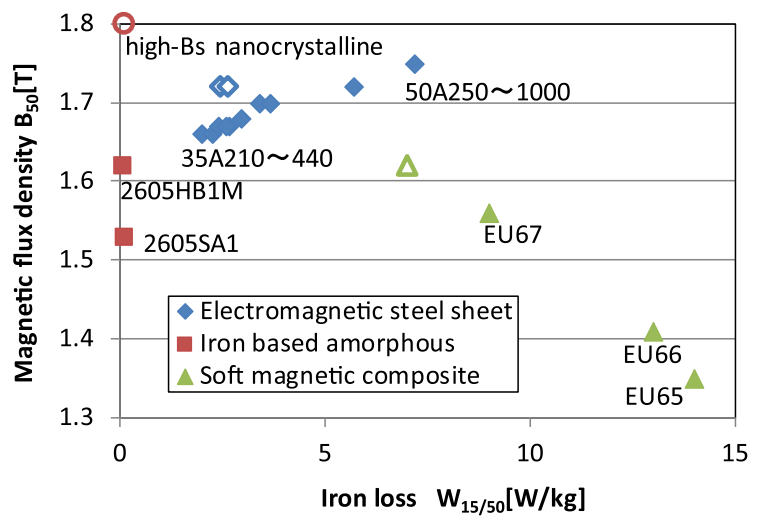

Fig. 1. Comparison of characteristics of soft magnetic materials 
Development of an Ultimate-high-efficiency Motor by utilizing High-Bs Nanocrystalline Alloy (Yuji Enomoto et al.)

Table 1. Comparison of magnetic properties

\begin{tabular}{|l|l|c|c|c|c|}
\hline \multicolumn{2}{|c|}{} & $\begin{array}{c}\mathrm{B}_{\mathrm{s}} \\
(\mathrm{T})\end{array}$ & $\begin{array}{c}\mathrm{H}_{\mathrm{c}} \\
(\mathrm{A} / \mathrm{m})\end{array}$ & $\begin{array}{c}\mathrm{W}_{15 / 50} \\
(\mathrm{~W} / \mathrm{kg})\end{array}$ & $\begin{array}{c}\mathrm{W}_{10 / 400} \\
(\mathrm{~W} / \mathrm{kg})\end{array}$ \\
\hline \multirow{2}{*}{$\begin{array}{l}\text { Nanocrysta } \\
\text { lline soft } \\
\text { magnetic } \\
\text { alloy }\end{array}$} & $\mathrm{FINEMET}^{\circledR} \mathrm{FT}-3 \mathrm{M}$ & 1.23 & 2.5 & - & 0.12 \\
\cline { 2 - 6 } & $\mathrm{Fe}_{82} \mathrm{Cu}_{1} \mathrm{Nb}_{1} \mathrm{Si}_{2} \mathrm{~B}_{12} \mathrm{P}_{2}$ & 1.76 & 3.0 & 0.20 & 1.5 \\
\cline { 2 - 6 } & $\mathrm{Fe}_{80.5} \mathrm{Cu}_{1.5} \mathrm{Si}_{4} \mathrm{~B}_{14}$ & 1.80 & 5.8 & 0.27 & 1.6 \\
\cline { 2 - 6 } $\begin{array}{l}\text { Iron based } \\
\text { amorphous }\end{array}$ & $2605 \mathrm{SA} 1$ & 1.75 & 3.0 & 0.19 & 1.5 \\
\cline { 2 - 6 } & $2605 \mathrm{HB} 1 \mathrm{M}$ & 1.63 & 2.0 & 0.13 & 1.5 \\
\hline \multirow{2}{*}{$\begin{array}{l}\text { Electromag } \\
\text { netic steel } \\
\text { sheet }\end{array}$} & $15 \mathrm{HX} 1000$ & 2.03 & 32 & 0.12 & 1.5 \\
\cline { 2 - 6 } & $35 \mathrm{H} 300$ & 2.03 & 49 & 2.4 & 18 \\
\cline { 2 - 6 } & $10 \mathrm{EX} 900$ & 1.8 & 20 & - & 5.7 \\
\hline
\end{tabular}

iron-based amorphous metals, they are classified as "ultralow core-loss type" (e.g., FINEMET® FT-3M), whose core loss is about one digit lower than that of iron-based amorphous metal, or "high-Bs type" (e.g., $\mathrm{Fe}_{80.5} \mathrm{Cu}_{1.5} \mathrm{Si}_{4} \mathrm{~B}_{14}$ ), whose Bs is higher than that of iron-based amorphous metal. As for high-Bs nanocrystallineline alloy, the core loss at $50 \mathrm{~Hz}$ is larger than that of iron-based amorphous metal; however, the core loss at $400 \mathrm{~Hz}$ is as low as that of ironbased amorphous metal. Although some research institutes have attempted to apply these nanocrystallineline alloys to motors $^{(15)-(17)}$, in regard to practical use, they are more brittle than iron-based amorphous metals, so many problems, such as machining, remain to be overcome.

2.2 Magnetic Characterization of Nanocrystalline Alloys As for nanocrystalline alloys, although their characteristics are compared in the literature, the results of actual measurement of magnetic their characteristics are scarce because they are not commercially available materials. Accordingly, the material under development (i.e., $\left.\mathrm{Fe}_{80.8} \cdot \mathrm{Cu}_{1} \mathrm{Mo}_{0.2} \mathrm{Si}_{4} \mathrm{~B}_{14}\right)$ was acquired and compared with other materials used in motors so far (see Table 1). A strip of nanocrystalline-alloy foil (manufactured by Hitachi Metals Co., Ltd.) with width of $19 \mathrm{~mm}$ was measured by a method called "single-plate-sample measurement" using a B-H loop analyzer manufactured by IFG Co., Ltd. ${ }^{(18)}$. As for this measurement, an excitation current is extended up to $50 \mathrm{~A}$ by an external power supply. Although a feature of this measurement device is that the $\mathrm{H}$ signals can be divided between two systems, in this measurement, two $\mathrm{H}$ coils are connected in reverse phase, and magnetic flux density was measured with one $\mathrm{H}$ coil. Moreover, when the magnetic flux density in the nanocrystalline-alloy single-plate sample was calculated, as for the cross-sectional area of the magnetic path, the thickness of the thin part of the sample was used as the thickness of the sample. The thickness of the sample was measured by micrometer (Mitutoyo BMD-25MJ, whose contact surfaces are both spherical), and several points on the nanocrystallineline alloy were measured, and the average value of the thin part was taken as the foil thickness. The evaluation results concerning two characteristics, namely, DC magnetization and AC loss, are respectively shown in the two graphs in Fig. 2. For reference, as comparison targets, measurement data concerning a ring sample of iron-based amorphous metal core 2605SA1 (space factor: 89\%) and catalog-stated data concerning magnetic steel sheet $35 \mathrm{H} 300$ are also listed ${ }^{(8)}$. From the measurement results on DC magnetization, it was

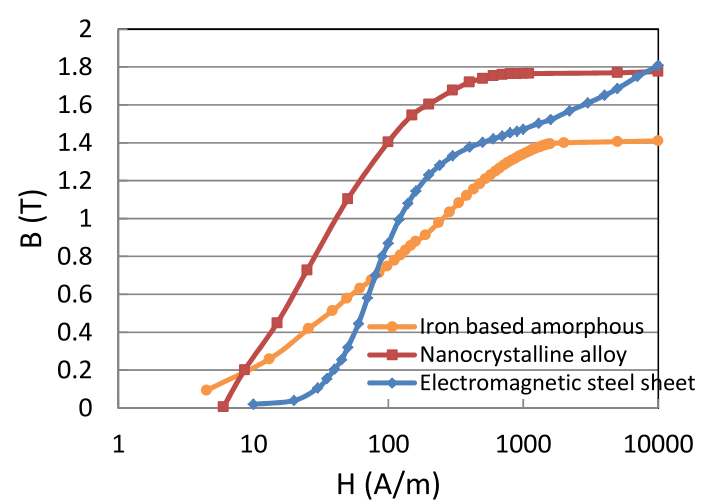

(a) DC magnetization characteristics

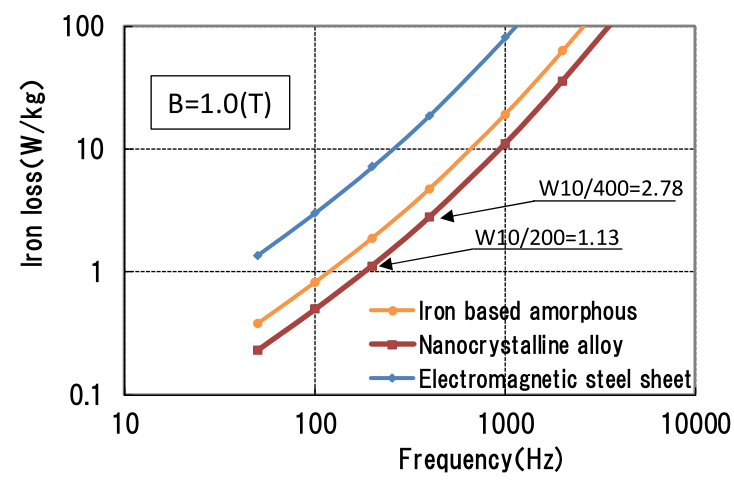

(b) AC loss characteristics

Fig. 2. Results of Evaluation results of magnetization characteristics of nanocrystalline alloy

confirmed that the magnetic flux density at the point that can be regarded as saturation $(\mathrm{H}=500 \mathrm{~A} / \mathrm{m}$ or more $)$ is about $1.8 \mathrm{~T}$ and that the value of saturation magnetic flux density of the high-Bs nanocrystalline alloy $\left(\mathrm{Fe}_{80.8} \cdot \mathrm{Cu}_{1} \mathrm{Mo}_{0.2} \mathrm{Si}_{4} \mathrm{~B}_{14}\right)$ shown in Table 1 was roughly obtained. It is clear that in regard to initial magnetization characteristics, the nanocrystallineline alloy has higher permeability than the iron-based amorphous metal, and its saturation magnetic flux density is as high as that of the electromagnetic steel sheet. Furthermore, from the AC-loss characteristic, the iron-loss coefficients can be estimated as hysteresis-loss coefficient $\mathrm{Kh}$ $=4.27 \mathrm{e}-3$ and eddy-current loss coefficient $\mathrm{Ke}=6.72 \mathrm{e}-6$. Although the measured iron loss is about 1.8 times larger than the core-loss value listed in Table 1, it is lower than the measured value for the ring sample of iron-based amorphous metal.

\section{Design to Improve Efficiency of Axial-gap Mo- tor}

\subsection{Loss Analysis of IE5 11-kW Axial-gap Motor}

A specification of an 11-kW axial-gap motor-with an iron core made of iron-based amorphous metal (2605SA1), manufactured as described in Ref. (7), is outlined in Table 2. A breakdown of the losses of this motor is shown in Fig. 3. The motor characteristics were evaluated by using a torque station, namely, TS-7700 manufactured by Ono Sokki Co., Ltd. The power and current were measured by power meter (WT-1806, manufactured by Yokogawa Measurement Co., Ltd.), and a torque was measured by torque detector (DD-106, manufactured by Ono Sokki Co., Ltd., maximum torque: $100 \mathrm{~N} \cdot \mathrm{m}$ ). The total loss of $437.7 \mathrm{~W}$ is the 
Development of an Ultimate-high-efficiency Motor by utilizing High-Bs Nanocrystalline Alloy (Yuji Enomoto et al.)

Table 2. Specification of IE5-11 kW axial gap motor

\begin{tabular}{|c|l|l|}
\hline \multicolumn{2}{|c|}{ Item } & \multicolumn{1}{c|}{ Specification } \\
\hline \multirow{4}{*}{ Target } & Output & $11(\mathrm{~kW})$ \\
\cline { 2 - 3 } & Rated speed & $3000(\mathrm{r} / \mathrm{min})$ \\
\cline { 2 - 3 } & Rated torque & $35(\mathrm{~N} \cdot \mathrm{m})$ \\
\cline { 2 - 3 } & Rated voltage & $200(\mathrm{Vrms})$ \\
\cline { 2 - 3 } & Rated current (line) & $35(\mathrm{Arms})$ \\
\cline { 2 - 3 } & Efficiency & $96.2 \%(\mathrm{IEF}: 95 \% \leqq)$ \\
\hline \multirow{5}{*}{$\begin{array}{c}\text { Detailed } \\
\text { dimensions }\end{array}$} & Slot/Pole & $12 / 10$ \\
\cline { 2 - 3 } & Magnet & NMF-12G+, $\phi 240 \times \phi 90 \times \mathrm{L} 11(\mathrm{~mm})$ \\
\cline { 2 - 3 } & Back yoke & $\phi 232 \times \phi 107 \times \mathrm{L} 12(\mathrm{~mm})$ \\
\cline { 2 - 3 } & Stator core & $\Phi 240 \times \phi 90 \times \mathrm{L} 67(\mathrm{~mm})$ \\
\cline { 2 - 3 } & Stator coil & $0.034(\Omega /$ phase@55 $\mathrm{C})$ \\
\hline
\end{tabular}

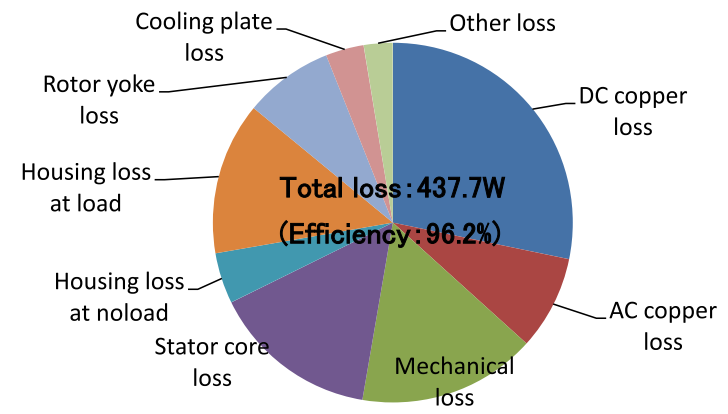

Fig. 3. Breakdown of loss of IE5-11 kW axial gap motor

actual value obtained by subtracting the rated motor output of $11 \mathrm{~kW}$ from the motor input power when the motor was continuously operated by using a general-purpose inverter. As for the breakdown of the loss, after the copper loss was separated (by using measured current and resistance values) and the mechanical loss, which was previously evaluated using a non-magnetized rotor, was subtracted, the iron loss (estimated by using three-dimensional magnetic-field analysis) was separated from the loss value due to the eddy current of each part. Although unknown loss of about $10 \mathrm{~W}$ remains, it is handled within the range of error.

If we look at the breakdown of losses, it can be seen that copper losses account for about one-third. It can be confirmed that although the core-loss ratio of the stator core utilizing iron-based amorphous metal is low, the AC loss generated in the housing, etc. is large. It is conceivable that these losses can be reduced by reducing the current value.

\subsection{Examination of Loss-reduction Factors}

(1) Application effect of high-Bs nanocrystalline alloy

The effects of utilizing a high-Bs nanocrystalline alloy for the stator core were verified in the case that the motor sizes were equal. Calculated torques of the motors with the ironbased amorphous metal core and the high-Bs nanocrystalline alloy, when residual magnetic flux density of the magnet was changed under fixing rated current, are compared in Fig. 4. Since the motor of the present design utilizes a ferrite sintered magnet (NMF-12G+, made by Hitachi Metals, Ltd.), it is designed to output rated torque $\mathrm{f} 35 \mathrm{~N} \cdot \mathrm{m}$ at $\mathrm{Br}$ of around $0.45 \mathrm{~T}$. According to the results of calculation of DC magnetization characteristics of the high-Bs nanocrystalline alloy (utilized as the stator iron core), used as input values of magnetic-field analysis, when residual magnetic flux density of the magnet was $0.45 \mathrm{~T}$, almost no change in output torque was observed. It is revealed by the figure that as a result of the value of the residual magnetic flux density of the magnet increasing,

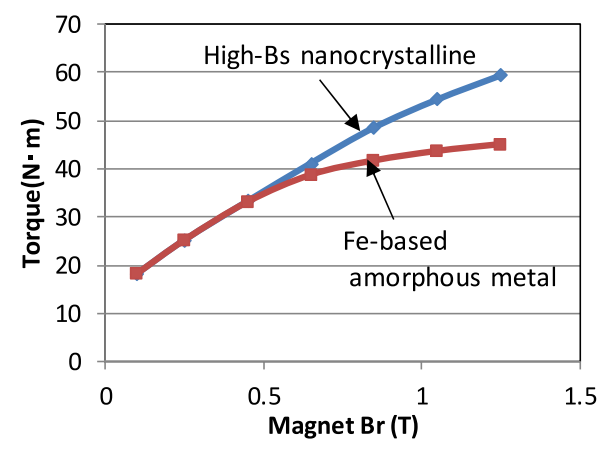

Fig. 4. Magnet Br/Torque

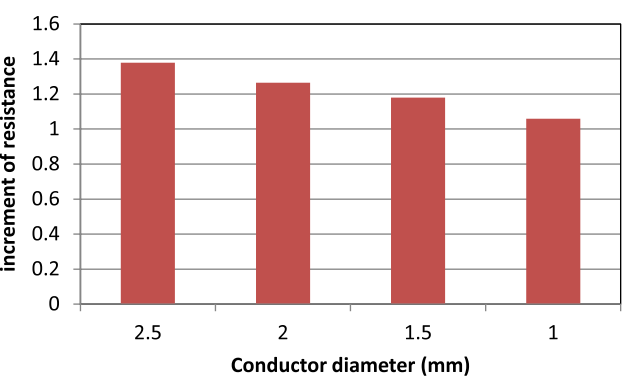

Fig. 5. Relation between conductor diameter and resistance

the difference in the output torques becomes large; therefore, when the high-Bs nanocrystalline alloy is utilized, it is necessary to increase the residual magnetic flux density of the magnet. It is also confirmed that an output torque of about 1.4 times can be obtained when a magnet with a residual magnetic flux density of about $0.84 \mathrm{~T}$ is used. It is assumed the magnets used in this study are bonded types, and even in the case of the surface-magnet type of axial-gap structure, a magnet that does not cause eddy-current loss was selected. If the motor is redesigned without changing such specifications as the axial length and outer diameter, it may be necessary to change the number of coil turns and the conductor diameter to increase the cross-sectional area of the conductor and reduce copper loss.

(2) Reduction of coil AC loss

The result of calculating (by magnetic-field analysis) the AC loss of the coil accompanying an increase in frequency is shown in Fig. 5. The fundamental frequency of coil current at the rated rotational speed of the motor is $250 \mathrm{~Hz}$. As frequency increases, copper loss increases due to the decrease in the effective area of the conductor due to the influences of the skin effect and the proximity effect. Copper loss with respect to wire diameter of the conductor in the case it is assumed that the fundamental frequency of coil current ranges from zero (direct current) to $250 \mathrm{~Hz}$ is shown in Fig. 5. It is clear from the figure that while copper loss is about 1.38 times when the conductor diameter is $\phi 2.6 \mathrm{~mm}$, copper loss hardly increases in when the conductor diameter is $1.0 \mathrm{~mm}$.

(3) Reduction of housing loss

The eddy-current loss generated in the housing occupies a large proportion of the total loss, about one-fifth, so reducing that loss greatly contributes to improving efficiency. The housing used for IE5 11-kW motors is designed on the premise of appropriating aluminum die-cast components used for the commercially available IE3 induction motors. 


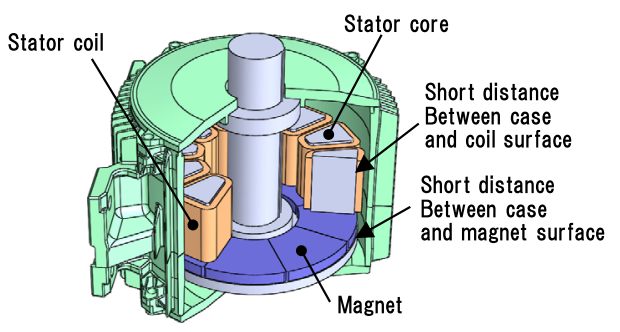

Fig. 6. Coil and magnet arrangement of axial gap motor

Table 3. Comparison of housing materials

\begin{tabular}{|l|l|l|}
\hline Item & $\begin{array}{l}\text { Conventional } \\
\text { Aluminum die } \\
\text { cast }(\mathrm{ADC} 12)\end{array}$ & $\begin{array}{l}\text { Ceremics } \\
\left(\mathrm{Al}_{2} \mathrm{O}_{3}\right)\end{array}$ \\
\hline \hline Impact strength & $81\left(\mathrm{~kJ} / \mathrm{m}^{2}\right)$ & Brittleness \\
\hline Tensile strength & $310(\mathrm{MPa})$ & $360(\mathrm{MPa})$ \\
\hline Bending strength & $200(\mathrm{MPa})$ & $310(\mathrm{MPa})$ \\
\hline $\begin{array}{l}\text { Linear expansion } \\
\text { coefficient }\end{array}$ & $21\left(\times 10^{-6} / \mathrm{K}\right)$ & $7.2\left(\times 10^{-6} / \mathrm{K}\right)$ \\
\hline $\begin{array}{l}\text { Thermal } \\
\text { conductivity }\end{array}$ & $96(\mathrm{~W} / \mathrm{m} \cdot \mathrm{K})$ & $24(\mathrm{~W} / \mathrm{m} \cdot \mathrm{K})$ \\
\hline Electric conductivity & $8.0 \times 10^{6}(\mathrm{~S} / \mathrm{m})$ & $>10^{-12}(\mathrm{~S} / \mathrm{m})$ \\
\hline
\end{tabular}

As for a typical radial motor, since the coil is arranged in the slot of the magnetic body, even when a large current flows in the conductor in the slot, the magnetic flux in the housing (arranged outside the magnetic body) hardly changes. Moreover, since the magnet rotor is also arranged inside the stator, in a few instances, the leakage flux from the magnet interlinks with the housing and becomes a loss. In the case of an axial-gap motor, as shown in Fig. 6, the outer peripheral of the stator coil is structured in opposition to the housing with a slight insulation distance between the coil surface and housing.

As a result of the above-described configuration, the magnetic flux generated by the coil current causes losses (such as eddy currents) in the aluminum housing. Furthermore, the outer surface of the magnet and the inner peripheral surface of the housing are also close to each other, so eddy-current loss is also generated in the housing by the leakage flux from the magnet.

A possible countermeasure for this situation is to make the resistivity of the material comprising the housing high. And to suppress the change of magnetic flux in the housing, it is necessary to make the housing nonmagnetic. Moreover, it is important to ensure sufficient mechanical strength and heat dissipation as functions of the housing.

In Table 3, properties of alumina $\left(\mathrm{Al}_{2} \mathrm{O}_{3}\right)$, which are considered to be applicable to the housing, and the currently used aluminum die-cast material (ADC12) are compared. Since alumina has low conductivity, it can reduce the occurrence of eddy-current loss; however, it must be designed with special attention paid to impact strength, thermal conductivity, and expansion due to temperature rise. Regarding the point at which the thermal conductivity of a material regarded as a housing material is lowered by about $75 \%$, by reducing the distance between the coil and the housing, the heat transfer between the coil and the housing was improved. Although the heat conductivity of the resin for holding the coil and the housing is low (i.e., $1 \mathrm{~W} / \mathrm{m} \cdot \mathrm{K}$ ), and the heat-transfer performance is degraded by maintaining the insulation distance, in the case that alumina is used as the housing material, since the insulation distance is not required, the heat-transfer performance can be made equal or higher than that of the conventional material by reducing the distance between the housing and the coil.

\section{Trial Manufacture of Motor using High-Bs Nanocrystalline Alloy}

4.1 Stator Core Composed of High-Bs Nanocrystalline Alloy The appearance of the stator core of an axial-gap motor using high-Bs nanocrystalline alloy is shown in Fig. 5. The high-Bs nanocrystalline alloy $\left(\mathrm{Fe}_{80.8} \cdot \mathrm{Cu}_{1} \mathrm{Mo}_{0.2} \mathrm{Si}_{4} \mathrm{~B}_{14}\right)$ used for the stator core is manufactured by Hitachi Metals. Since the foil band of highBs nanocrystal alloy-which has been heat-treated to ensure its magnetic properties - is vitreous and fragile, a laminated core is manufactured by vacuum impregnation of resin ${ }^{(19)}$. From a block, a core of arbitrary shape is created by wire electric-discharge machining. In this study, the general dimensions were obtained by cutting at an angle of 30 degrees, and corners were made by corner chamfering with a grinder. The surface cut by wire electrical-discharge machining is subjected to a special etching process so as to prevent conduction between the foil bands. This core shape has the same as the core shape of an axial-gap motor using general iron-based amorphous metal; accordingly, it is conceivable that it can be mass-produced in the future by the conventional strip-lamination method ${ }^{(7)}$.

The result of measuring the magnetic characteristics of the above-described core shape is shown in Fig. 7. The results are generally consistent with those in given in Table 1 and Fig. 2. As iron loss value at $1 \mathrm{~T}$ and $200 \mathrm{~Hz}, 1.53 \mathrm{~W} / \mathrm{kg}$ is about 1.4 times larger than iron loss when it is evaluated with a single plate $(1.13 \mathrm{~W} / \mathrm{kg})$, and the degradation factor (i.e., building factor, BF) from the material-characteristic values listed in Table 1 is also within two times. In the case of an amorphous core, when its state is changed from a foil band (material) to an iron core, the core-loss characteristic deteriorates and core loss increases by about three times; however, it was confirmed that the stator core composed of high-Bs nanocrystal alloy manufactured in this trial has a BF within about two times. In the raw-material state, core loss is lower than that of iron-based amorphous metal, and BF is also small, so it can be expected that the loss in the motor will also be small.

\subsection{Fabrication of Prototype Motor A cross-} sectional view of the motor structure and a perspective external view are shown in Fig. 9. The motor designed to utilize high-Bs nanocrystal alloy as the stator core was designed and fabricated with the same core shape as a basic IE5 11-kW motor; therefore, mold parts could be bobbins used for the winding and peripheral parts. Since the stator core was manufactured by using bands of nanocrystalline alloy foil with width of $40 \mathrm{~mm}$, it was manufactured as a structure in which the axial length of the stator core $(67 \mathrm{~mm})$ was divided in two.

The stator core and stator coil were fixed to the ceramic housing by resin molding in the same manner as the conventional method. However, to increase the bonding area with the housing (because a high-thermal-conductivity resin 


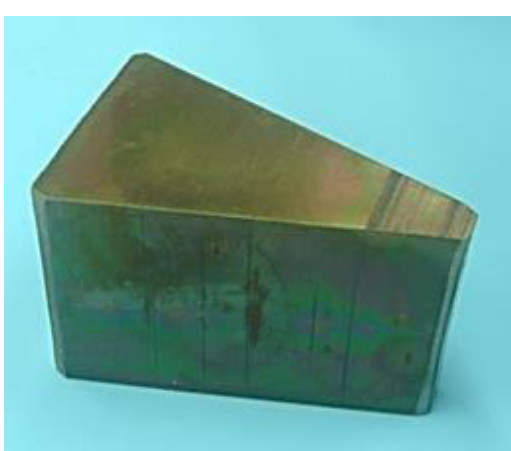

Fig. 7. Appearance of high-Bs nanocrystalline alloy core

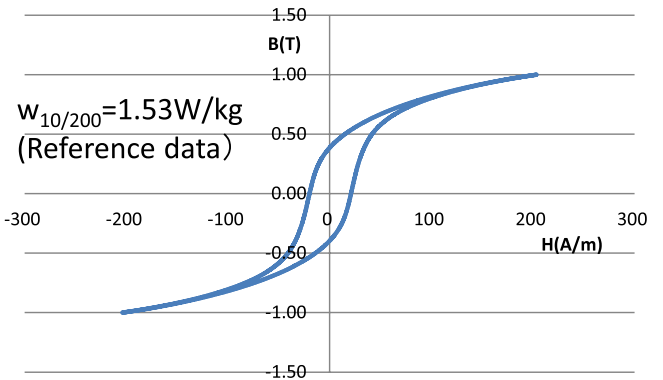

Fig. 8. BH characteristic of stator core

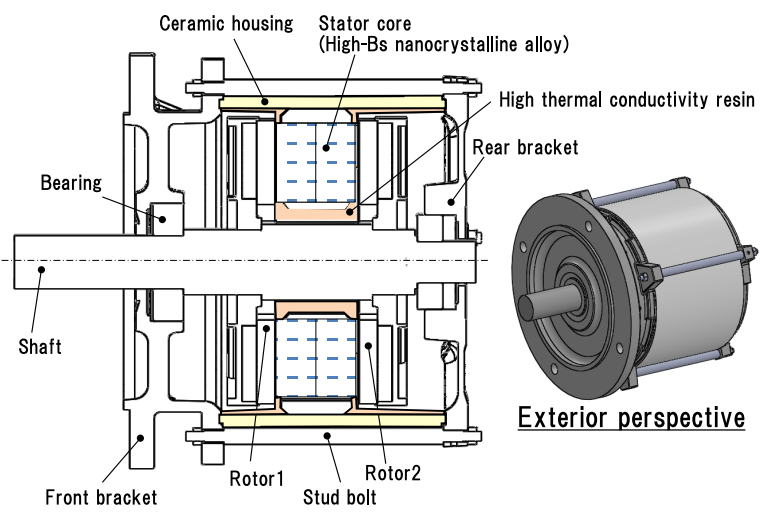

Fig. 9. Structure of prototype motor

is used), the inner part of the housing (i.e., the part other than the part in which the stator is arranged) has a contact area as a bonding surface with the resin of about 2.5 times. As a result of this structure, the heat-transfer performance and the statorholding strength are enhanced. On the inner surface of the resin, a draft taper of $1.5^{\circ}$ is provided for releasing the mold. The ceramic housing has higher hardness, tensile strength, and bending strength than an aluminum die-cast one, so the proposed structure is also effective in preventing impact with the inner-wall surface of the stator during assembly because it is weak against impact. A bonded magnet $(\mathrm{Br}=0.8 \mathrm{~T})$ molded by injection molding was adopted as the rotor magnet. The magnet has a fan shape with eight divisions in the circumferential direction, and CFRP (carbon-fiber-reinforced plastic) is placed around the outer edge of the magnet as filament winding to retain the magnet against its centrifugal force. In regard to the assembly as a motor, the cylindrical ceramic-housing stator was held by axially clamping the front- and rear-end brackets with stud bolts.

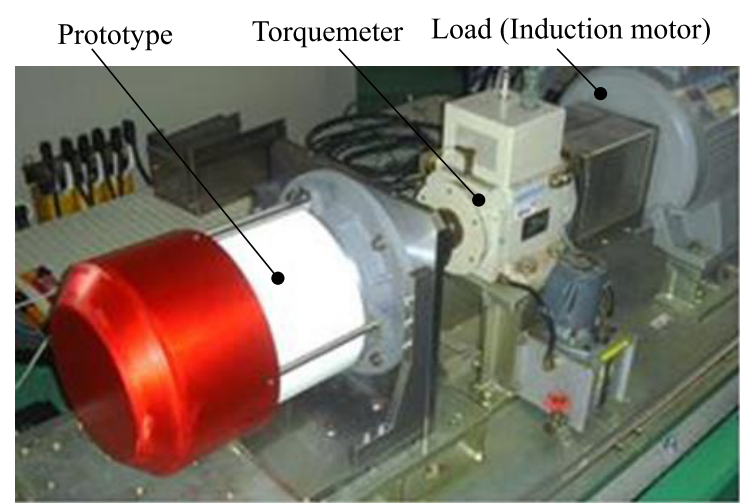

Fig. 10. Externals of evaluation test

\subsection{Evaluation of Prototype Motor}

(1) No-load characteristics

The no-load characteristics of the prototype motor at constant speed were measured. In particular, the effect of reducing AC resistance was confirmed by setting the coil wire diameter to $\varphi 1.0 \mathrm{~mm}$. The results of measuring (by using an LCR meter) the increase in coil AC resistance due to increasing frequency confirm that $\mathrm{AC}$ resistance hardly increases up to $200 \mathrm{~Hz}$ ( $3000 \mathrm{r} / \mathrm{min}$ with eight poles). As for resistance, it was confirmed that one-phase resistance value at room temperature was reduced to $20 \mathrm{~m} \Omega$, namely, about two thirds of the IE5-motor design value. The induced voltage also changed linearly with increasing number of revolutions, and the phase voltage was $0.18 \mathrm{Vp} /(\mathrm{rad} / \mathrm{s})$, which was almost as designed. As for no-load loss (i.e., mechanical loss plus iron loss), according to the results of evaluating the motor under external drive, under the assumption that mechanical loss is $70 \mathrm{~W} @ 3000 \mathrm{r} / \mathrm{min}$ (equivalent to that of a IE5 11-kW motor), the rated no-load iron loss was $83 \mathrm{~W}$, which is consistent with the estimated value by calculation.

(2) Measurement of load characteristic

The appearance of the load-characteristic test bench is shown in Fig. 10. Since the prototype motor is a flangemounted motor, it was evaluated by using a testing apparatus with a high-rigidity L-shaped bracket. The torque meter used by this test bench was a DD-1506B by Ono Sokki Co., Ltd. (maximum torque: $500 \mathrm{~N} \cdot \mathrm{m}$; accuracy $\pm 0.2 \%$ ); the power meter was a WT-1600 manufactured by Yokogawa Measurement Co., Ltd.; and for measuring current, an AC crank probe (model 96001 manufactured by Yokogawa Measurement Co., Ltd.) was used. The analog input of the power meter has a resolution of 16 bits, and it measured power without setting the line filter. The accuracy of the power and current measurements was about $0.5 \%$ of the measurement range. To drive the prototype motor, an industrial general-purpose inverter (WJ200-110LF; manufactured by Hitachi Industrial Equipment Systems Co., Ltd.) was used. The carrier frequency of PWM was set to $8 \mathrm{kHz}$, and since the prototype motor is a surface-magnet type, the inductance values of the inverter were set as approximately equivalent to $\mathrm{L}_{\mathrm{d}}$ and $\mathrm{L}_{\mathrm{q}}$, and the motor is mostly driven by the q-axis current (with current phase angle). The current-torque characteristic of the motor is shown in Fig. 11. The torque characteristics of the prototyped motor agree with the analysis values, so it can be confirmed that the torque constant is improved compared to 


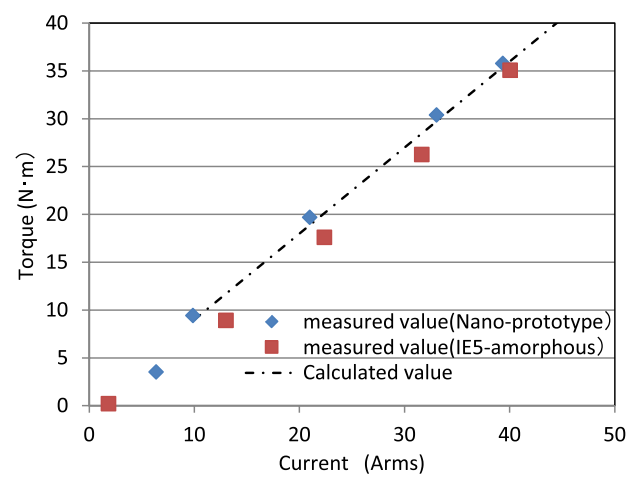

Fig. 11. Current-Torque

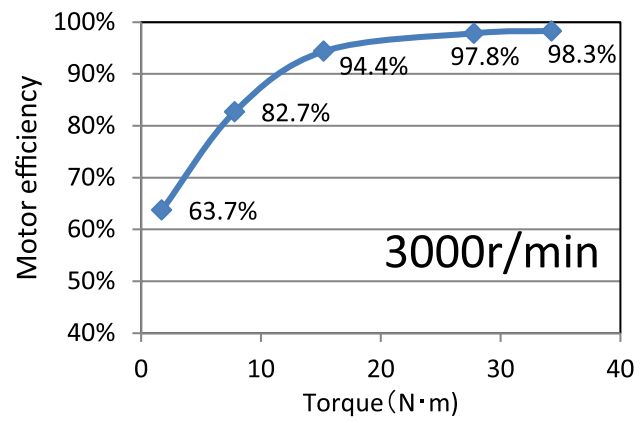

Fig. 12. Motor efficiency

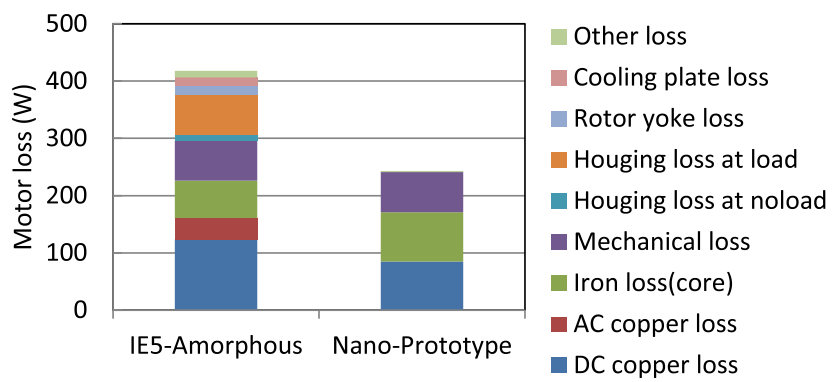

Fig. 13. Comparison of motor losses

that of the IE5 amorphous motor.

The results of measuring motor efficiency are plotted in Fig. 12. This plot represents the characteristic after the temperature rise during continuous drive at rated torque. Compared to the IE5 amorphous motor, the prototype motor can reduce phase loss by half under rated operation, and motor efficiency of $98.3 \%$, namely, efficiency improved by about $2 \%$ compared to the IE5 amorphous motor, is confirmed.

The loss breakdown under rated operation, in comparison with that for the IE5 amorphous motor, is shown in Fig. 13. In both cases, phase loss is a measured value, and copper loss and mechanical loss are measured values, and the other losses (including iron loss of the stator core) are separated as calculated values. The main loss reductions are itemized as follows: reduction of DC copper loss by enhancement of magnetic flux density of the iron core; reduction of AC copper loss by adopting a thin coil wire (reduced diameter); and reduction of eddy-current loss generated in the housing. As for the prototype motor, although iron loss of the stator core is increased, motor efficiency is improved in conjunction with other loss-reduction effects.

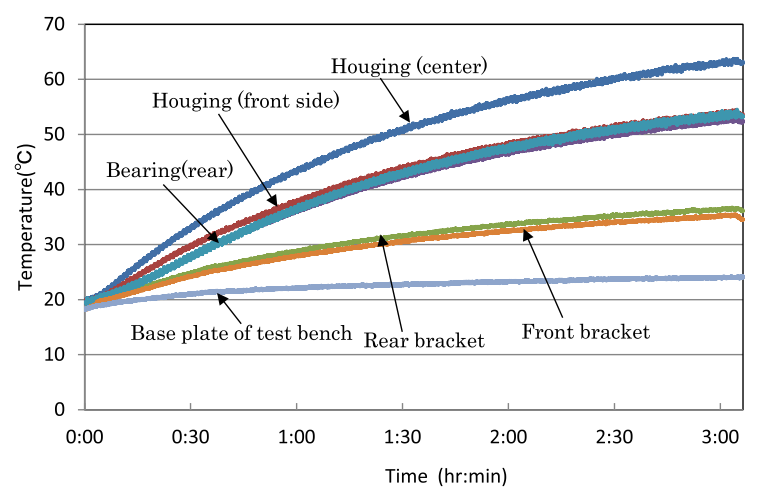

Fig. 14. Confirm temperature rise

\section{(3) Confirmation of rise in motor temperature}

The results of measuring the rise in motor temperature are plotted in Fig. 14. As for the housing of the prototype motor is, as mentioned above, it is made of a material with a low coefficient of linear expansion; consequently, it is necessary to be aware of rapid temperature changes and high temperature rises. The results of a test on temperature rise under rated operating conditions confirmed that in terms of the temperature rise of the housing surface (center point) is about $45 \mathrm{~K}$ and the stress due to the difference between expansions of the resin and the housing, the material strength of the ceramic housing is within the acceptable range.

As for the prototype motor, the temperature rise in the motor coil-without using a cooling means such as an external fan like that located at the rear end of a general industrial motor-is $55 \mathrm{~K}$. And it was confirmed that the prototype motor sufficiently satisfies heat-resistance class B (within $130^{\circ} \mathrm{C}$.) even when ambient temperature is $40^{\circ} \mathrm{C}$. It was also confirmed that the change in the current was small even after the temperature rise under rated operation for about three hours, and the change in the current was 39.6 to 40.1 Arms, namely, $1.5 \%$ or less.

\section{Concluding Remarks}

Under the aim of increasing the efficiency of an axial-gap motor, a prototype motor was designed on the basis of an IE5 11-kW axial-gap motor (with motor efficiency 96\%) and experimentally demonstrated to achieve efficiency of $98 \%$. Based on that design, a motor was designed and prototyped by focusing on factors that can reduce losses, namely, adopting a ceramic housing, thinning the coil conductor, and utilizing nanocrystalline material for the stator core, and the effectiveness of the prototype motor was confirmed by experimentally evaluating its characteristics. According to the results of that evaluation, the motor demonstrated motor efficiency of $98.3 \%$ at $3,000 \mathrm{r} / \mathrm{min}$ and $11-\mathrm{kW}$ rated drive. In addition, it demonstrated class-B heat resistance $\left(130^{\circ} \mathrm{C}\right)$ in a temperature-rise test. The findings obtained in this study are summarized below.

(1) High-Bs nanocrystalline materials were obtained, and the magnetic characteristics of the stator-core configurations for single-plate and axial-gap motors were evaluated.

The results of that evaluation confirm literature values, appropriate magnetization characteristics, and 
iron loss levels.

The core loss in the stator core state is $1.5 \mathrm{~W} / \mathrm{kg}$, at $1 \mathrm{~T}$ and $200 \mathrm{~Hz}$, which is about $20 \%$ lower than the ring-sample measurement data for a stator made of iron-based amorphous metal, and the magneticproperty deterioration rate (BF: building factor) is low (i.e., 2.0 or less).

(2) The use of a ceramic housing and thinning of the coil wire showed that $\mathrm{AC}$ loss in an axial-gap motor.

\section{References}

( 1 ) Japan Energy Center website, http://www.eccj.or.jp/

( 2 ) R. Abe: "Energy Efficiency in Motor Driven Systems 2007 Conference attendance report", JEMA Institutional paper Electric machine, 14 (2007.10)

( 3 ) IEC 60034-30-1: Rotating electrical machines - Part 30-1: Efficiency classes of line operated AC motors (IE code) (2014)

( 4 ) Z. Wang, Y. Enomoto, M. Ito, R. Masaki, S. Morinaga, H. Itabashi, and S. Tanigawa: Development of a Parmanent Magnete Motor Utilizing Amorphous Wound Cores, IEEE Transactions on Magnetics, Vol.46, No.2 (2010)

( 5 ) Hitachi News Release: "Highly Efficient Industrial $11 \mathrm{~kW}$ Permanent Magnet Synchronous Motorwithout Rare-earth Metals-Realizing IE4 Class Efficiency Standard with a Smaller Motor-", http://www.hitachi.com/ New/cnews/120411.html (2012)

( 6 ) Hitachi News Release: "Development of IE5-class Efficiency Standard Amorphous Motor-Material Evaluation \& Design Technology to Achieving 96\% Motor Efficiency_", http://www.hitachi.com/New/cnews/month/ 2014/07/140709.html (2014)

( 7 ) Y. Enomoto, H. Tokoi, T. Imagawa, T. Suzuki, T. Obata, and K. Souma: "Development of IE5-class efficiency standard amorphous motor", Journal of the Japan Society of Applied Electromagnetics and Mechahincs, Vol.24, No.3, pp.258-263 (2016) (in Japanese)

( 8 ) Nippoin steel corporation data sheet: "Hilitecore Homecore (Non-oriented electrical steel sheets)", D005je_01_201210p (2012)

( 9 ) Hitachi Metals, Ltd catalog: "AMORPHOUS ALLOY STRIP Metglas®”, Catalog No.HJ-B10-D (2017)

(10) Y. Enomoto: "Recent Development Trends in Soft Magnetic Composites and Their Application to Motors", Magnetics Japan, Vol.1, No.9, pp.424-431 (2006) (in Japanese)

(11) M. Ohta and Y. Yoshizawa: "Effect of Heating Rate on Soft Magnetic Properties in nanocrystalline $\mathrm{Fe}_{80.5} \mathrm{Cu}_{1.5} \mathrm{Si}_{4} \mathrm{~B}_{14}$ and $\mathrm{Fe}_{82} \mathrm{Cu}_{1} \mathrm{Nb}_{1} \mathrm{Si}_{4} \mathrm{~B}_{12}$ Alloys", Appl. Phys. Express 2, 023005 (2009)

(12) M. Ohta: "Development of High Bs Nanocrystalline Alloy Cores and Their Medium-Frequency Applications", HitachiMetals Technical Review, Vol.34, pp.18-23 (2018) (in Japanese)

(13) Investigating R\&D Committee for Next-Generation Application-Specific Electric Motors and Component Technology: "Next-Generation ApplicationSpecific Electric Motors and Component Technology", IEEJ Technical Report, No.1405, pp.53-54 (2017)

(14) M. Ohta and R. Hasegawa: "Soft Magnetic Properties of Magnetic Cores Assembled With a High Bs Fe-Based Nanocrystalline Alloy", IEEE Transactions on Magnetics, Vol.53, No.2 (2017)
(15) Y. Nishikawa, T. Kojima, T. Segawa, K. Tanimoto, T. Ogawa, and K. Kinjyo: "Highly Efficiency Motor Using Soft Magnetic Material with SuperLow Ilon Loss", Panasonic Technical Journal, Vol.62, No.2, pp.43-48 (2016) (in Japanese)

(16) T. Nonaka, S. Zeze, S. Makino, and M. Ohto: "Research of the Motor with Nanocrystalline Soft Magnetic Alloy Stator Cores”, IEE of Japan, RM-17124, pp.13-18 (2017) (in Japanese)

(17) M. Inoue, S. Odawara, M. Ieki, Y. Kato, and K. Fujisaki: "Evaluation of iron loss on IPMSM using nanocrystalline soft magnetic material by electromagnetic field numerical calculation", IEE Japan, LD-16-19 (2016)

(18) IFG corporation catalog: "BH Roop Analyzer (IF-BH550)" http://www.ifg. $\mathrm{jp} /(2011)$

(19) M. Ohta, R. Hasegawa, and H. Itabashi: "Development of Block Cores Comprising High-Bs Nanocrystalline Alloy Ribbon”, IEEE Transactions on Magnetics (2018)

Yuji Enomoto (Senior Member) received Ph.D. degrees in electrical

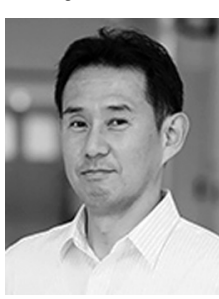
and comunication engineerring from Tohoku University, Sendai, Japan, in 2006, respectively. He joined Hitachi in 1987. First, he was engaged in research on automation systems and electrical equipment production technology at the Production Technology Laboratory. Transferred to Hitachi Laboratory in 2001, engaged in motor design and production technology research. Currently, Chief Researcher at Center for Technology Innovation-Controls. He is a Professional engineer JP. (Electrical and Electronic Engineerring). He is a senior member of IEE Japan and a member of JSAEM.

Kenta Deguchi (Member) received the B.S. and M.S. degrees in electrical and electronic engineering from Shinshu University, in 2009 and 2011, respectively. From 2011 to 2013 he was with the Hitachi Research Laboratory, Hitachi, Ltd. Since 2014 he has been with the Research \& Development Group, Hitachi Ltd., where he works on motor design.

Takao Imagawa

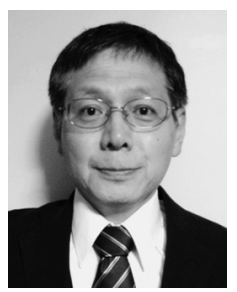

(Non-member) received B.Eng. degree and M.Eng. degree from the Univ. of Nagoya in 1980 and 1982. From 1982 to 1993 he was in Hitachi Research Laboratory Hitachi, Ltd. From 1993 to 2005 he was in Hitachi Global Storage Technologies Japan, ltd. From 2005 he is in Advanced Research Laboratory and Central Research Laboratory Hitachi, Ltd. His research interests are Magnetism and Measuring technic of magnetic materials. 